\title{
A holistic view of the organizational knowledge dynamics
}

\author{
Constantin BRĂTIANU, \\ Bucharest University of Economic Studies, Bucharest, Romania \\ Academy of Romanian Scientists, Bucharest, Romania \\ constantin.bratianu@gmail.com
}

\begin{abstract}
The purpose of this paper is to present a holistic view of the organizational knowledge dynamics, as an alternative to the current research focusing on different aspects of this complex and nonlinear phenomenon. Organizational knowledge is a semantic construct which has been developed as a result of growing importance of knowledge as a strategic resource, and it constitutes an integration of all forms of knowledge co-existing within an organization. Organizational knowledge varies in time and its dynamics is vital for organizational growth and for achieving a competitive advantage. Our approach is based on metaphorical thinking and on critical analysis of the present research concerning organizational knowledge and organizational intellectual dynamics. Going beyond the iceberg and stocks-and-flows metaphors, our research is based on the energy metaphor and the entropy law. The conceptual approach used and the final results obtained demonstrate the importance and utility of the holistic view in understanding more profoundly the complexity of the organizational knowledge dynamics.
\end{abstract}

Keywords: knowledge creation, knowledge acquisition, knowledge loss, knowledge sharing, metaphors, organizational knowledge

JEL Classification: D58, D83.

\section{Introduction}

According to the philosophical tradition, most of the research developed in the Western countries is based on an atomistic view and objective methods for measuring different attributes of objects and their interactions, while in the Eastern countries it is favored the holistic view and the qualitative research. As remarked by Nisbett (2003, p. 82), "Westerners have an analytic view focusing on salient objects and their attributes whereas Easterners have a holistic view focusing on continuities in substances and relationships in the environment". Research into knowledge management is not an exception, fact for which the 
great majority of books and papers in this domain have an analytical approach. The present paper changes the focus from the components of the organizational knowledge dynamics and their attributes toward the whole organization and the correlations between components which contribute to the integral dynamics. This view is useful in understanding the behavior of the knowledge intensive firms (Bolisani et al., 2016), and in creating successful knowledge strategies (Bratianu\&Bolisani, 2015; Bolisani\&Bratianu, 2017).

According to Russ (1999, p. 64), "Holism means that a system's capacity for action exceeds the individual or summed capabilities of its parts. The system as a whole comprehends more about its environment, can process vastly more information, has a broader repertoire of symbolic language, has more advanced reproductive capabilities, possesses a more effective survival potential, and exerts greater control over its environment than do its parts". Using the holistic perspective, an organization is considered as an open system which exchanges information and knowledge with the external business environment through its interface. Also, the holistic view allows for considering the entropy law and its consequences on the distribution of knowledge within organization (Atkins, 2010; Georgescu-Roengen, 1999). The concept of entropy has been introduced in Physics by R. Clausius in 1865 in order to explain the transformation of mechanical energy into thermal energy, and the energy transfer from a hot body toward a cold body (Atkins, 2010; Handscombe\& Patterson, 2004). Unlike mechanical processes which are reversible, thermodynamic processes are irreversible and entropy has been introduced to measure the degree of that irreversibility. Also, entropy is related to the changing process of order into disorder which can be evaluated by the probability of a given arrangement of microstates to create a macrostate of the system. Entropy indicates the direction of change, being considered a time arrow. However, order and disorder are relative terms and they can be described only with respect to an initial framework of order (Ben-Naim, 2012; Chalidze, 2000; Handscombe\& Patterson, 2004). As Georgescu-Roengen (1999, p. 142) posits, "We associate the random order with disorder because it does not correspond to the analytical order we expect to find in nature".

The holistic view of the organizational knowledge dynamics leads us also to the second law of thermodynamics or the entropy law: "The entropy of the universe increases in the course of any spontaneous change" (Atkins, p. 49). Here, the word universe means the system considered with its environment. However, the law does not explain how to measure the entropy change, but its increase is due to a change in the probability distribution of the microstates of the system. In our case, the macrostate of organizational knowledge is a result at a given moment of the probability distribution of the individual knowledge of all 
the employees. The second law of thermodynamics is important not only in Physics but in the whole science, and thus in our understanding of the universe, because "it provides a foundation for understanding why any change occurs" (Atkins, p. 37).

\section{Methodology}

The present paper is a result of a conceptual approach based on the metaphorical thinking and on a critical analysis of the literature dedicated to organizational knowledge dynamics. Cognitive scientists show through their research that our mind is inherently embodied, and that conceptual thinking is largely metaphorical (Fauconnier\& Turner, 2002; Lakoff\& Johnson, 1999; LeDoux, 1998; Pinker, 2008). A metaphor is a mapping process (Figure 1) from a known semantic domain - the source domain - onto a less known semantic domain the target domain. Usually the source domain contains a semantic field of a concrete, physical object of the experiential realm while the target domain contains a semantic field of an abstract concept (Moser, 2000). Thus, by using a metaphor we enrich the meaning of a new concept by transferring some attributes from the well-known concept considered in the source domain. That means that the new concept reflects the semantic structure and attributes of the source concept. However, not all the attributes are mapped from the source domain onto the target domain because not all of them may describe the new concept. Also, during the metaphorical analysis we identify some of the attributes specific to the target domain which are not found in the source domain. One of the most known metaphorical process people use is expressing time in terms of space (Boroditsky, 2000; Grondin, 2010; Lakoff\& Johnson, 1980). In the case of knowledgeAndriessen (2008) explains that thinking metaphorically is inescapable because that is the way human mind works. "However, the unconscious choice of metaphor has enormous impact on how we reason about knowledge, what is highlighted and what is hidden, what is seen in organizations as problems and what is understood as solutions" (Andriessen, 2008, pp. 5-6). 
Figure 1-Mapping from the source domain onto the target domain

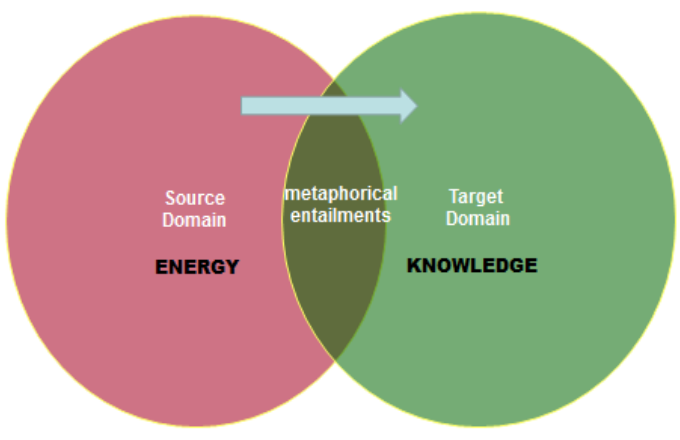

We analyzed the most frequently used metaphors in the knowledge management research and in the next section we will present some conclusions concerning the limitations of these metaphors in explaining knowledge, knowledge dynamics and organizational knowledge dynamics. Then, we will present the new openings offered by the energy metaphor and how we may get a better interpretation of the organizational knowledge dynamics by using it and the second law of thermodynamics.

\section{Basic metaphors used in knowledge management}

The first generation of metaphors used in explaining the concept of knowledge considered in the source domain objects or stocks of different objects (Andriessen, 2006, 2011; Bolisani et al., 2012; Borgo\&Pozza, 2012; Davenport \&Prusak, 2000; Leonard-Barton, 1995). These metaphors transferred many attributes specific to physical objects to the knowledge concept. Thus, within the framework of these metaphors knowledge can be accumulated, stored, retrieved, distributed and packaged. A rather special metaphor is that using the iceberg in the source domain, due to its simplicity and intuitiveness for representing the explicit knowledge as the visible part of the iceberg, and the tacit knowledge as the hidden part of the iceberg (Nonaka\& Takeuchi, 1995). For instance, referring to the explicit knowledge, Nonaka and Takeuchi $(1995$, p. 8) remark: "Japanese companies, however, have a very different understanding of knowledge. They recognize that the knowledge expressed in words and numbers represents only the tip of the iceberg". A common feature of all these metaphors is that they induce the idea of a knowledge entity like a physical object which is solid and static, like all the other physical assets of a company. This resourcebased view of knowledge (Grant, 1996; Spender, 1996) constrains knowledge 
only to its economic role. However, knowledge is not a self-contained substance like any other physical resources. "The most prominent feature of knowledge, compared with physical resources and information, is that it is born of human interaction. It is not a self-contained substance waiting to be discovered and collected. Knowledge is created by people in their interactions with each other and the environment" (Nonaka et al., 2008, p. 7).

The second generation of metaphors is characterized by the concepts fluid, flow or the expression stock-and-flow used in the source domain (Davenport \&Prusak, 2000; Nissen, 2006; Nonaka et al., 2008; O’Dell \& Hubert, 2011). By changing the choice for the source domain from objects to fluid, flow, or stockand-flow researchers induced the idea of knowledge dynamics. "We can denote knowledge stock as the amount or 'level' of knowledge possessed at a particular time in an organization, while knowledge flows identifies knowledge that is transferred from one economic player to another. According to this interpretation, knowledge flows can affect the amount of knowledge stocked by the two players" (Bolisani\&Oltramari, 2012, p. 280). These new metaphors change the paradigm of knowledge understanding by emphasizing its fluid nature and the possibility of flowing through the organization. That is, the new metaphors introduce the concept of knowledge dynamics (Nissen, 2006; Nonaka et al., 2008). The flow of knowledge is important both in space and in time. For instance, when one shift is replaced by another one in a plant or in a hospital, knowledge flows in time from one shift to the other. These metaphors became very popular due to the similarities between a fluid flow and the process of knowledge transfer in social interaction. However, a fluid flows as a result of a pressure difference between two points in space, an aspect which is ignored in the knowledge flow and which may create confusion in many practical situations.

All of these metaphors created in the first two generations induce the idea of linearity in treating knowledge, which means a powerful temptation in applying the Newtonian logic in knowledge processing. For instance, in many reporting procedures of the intellectual capital which is based on knowledge content there are indicators which represent physical objects and financial resources which change completely the meaning of those evaluations (Bejinaru, 2017; Dumay, 2009, 2016; Elena Perez et al., 2015; Guthrie et al., 2012; Habersam et al., 2013). Counting the number of computers, patents, research contracts, professors in a university, money obtained through research grants etc. cannot measure the value of intellectual capital or knowledge since there are two different categories of entities: tangible and intangible (Bratianu, 2014; Bratianu\&Bejinaru, 2017). Also, there are two different models of thinking which affects our understanding and actions: linear thinking and nonlinear thinking 
(Bratianu, 2015; Bratianu\&Vasilache, 2010). Linear thinking is based on the idea that the correlation between the outputs and the inputs of a given process is linear. That means that the output variables are proportional to the input variables. For instance a salary computed on the number of working hours and a certain financial quantum per hour is a linear outcome. When output variables are correlated to input variables based on mathematical equations which are not linear (i.e. polynomial, exponential, logarithm etc.), then the process is nonlinear. For instance, mental processes are fully nonlinear, and knowledge as a result of such a process is nonlinear. Bratianu (2009) demonstrated that knowledge cannot fulfill the requirements of a linear mathematical space, which leads logically to the conclusion that knowledge is nonlinear. Applying linear solutions to nonlinear problems without too much reflection on the approximation scale may lead to serious errors in interpreting the final results.

\section{The dynamic theory of organizational knowledge creation}

Nonaka was the first to elaborate a consistent and coherent theory of organizational knowledge creation, which contains also some fundamental ideas about the organizational knowledge dynamics (Nonaka, 1994; Nonaka\& Takeuchi, 1995; Nonaka et al., 2008). Based on the iceberg metaphor, Nonaka defined first as fundamental the two concepts of knowledge: tacit knowledge and explicit knowledge. Tacit knowledge is highly personal and hard to formalize. It can be defined loosely as being "Subjective insights, intuitions, and hunches fall into this category of knowledge. Furthermore, tacit knowledge is deeply rooted in an individual's action and experience, as well as in the ideals, values, or emotions he or she embraces" (Nonaka\& Takeuchi, 1995, p. 8). Thus, tacit knowledge is a construct which contains all forms of knowledge which are processed in the cognitive unconscious zone of the brain. Complementary, all forms of knowledge which are processed in the conscious zone of the brain are incorporated into the construct of explicit knowledge. The dynamic theory of organizational knowledge creation is focused on the continuous interactions between these two forms of knowledge, interactions which lead to four distinct transformations: socialization, externalization, combination, and internalization. They form together the SECl model and generate a knowledge spiral, which represents essentially the knowledge creation process: "Knowledge emerges from the subjectivity of actors embedded in a context and is objectified through the social process. Knowledge is created from the synthesis of thinking and action by individuals interacting both within and beyond organizational boundaries. This knowledge then forms a new praxis for interaction that 
becomes the basis for new knowledge again, through the knowledge-creating spiral" (Nonaka et al., 2008, p. 18).

Socialization is the process of transferring tacit knowledge from one person to another within a social context. It is a form of knowledge sharing when perception and imitation become more important than using language. It is a process specific mostly to the Japanese culture. Externalization is a conversion of tacit knowledge into explicit knowledge through a natural language. In other words it is a transformation of experience into expressible and explainable knowledge. Combination is an exchange of explicit knowledge between individuals within a social context called by Nonaka Ba (Nonaka, 1994; Nonaka\& Takeuchi, 1995). The last process is internalization, which transforms explicit knowledge into tacit knowledge completing the knowledge cycle. The SECI model reflects in a detailed manner the process of learning by doing within a given social context or praxis. However, in using this model in knowledge management people should be aware of some limitations due to the idealistic design of these knowledge transformations (Bratianu, 2010, 2013; Bratianu\&Orzea, 2010).

Organizational knowledge creation implies the extension of the $\mathrm{SECl}$ model to the whole organization. Nonaka and Takeuchi (1995) present a diagram of that model having an epistemological dimension and an ontological dimension. Along the epistemological dimension tacit and explicit knowledge interact and lead to the externalization and internalization processes at the individual level. Along the ontological dimension knowledge expands from individual level toward group and organizational levels through socialization and combination. This model elaborated by Nonaka and his co-workers is a good instrument for understanding the social dimension of knowledge creation, but it has some limitations when used as a descriptive model of the organizational knowledge dynamics.

\section{The entropic perspective of the organizational knowledge dynamics}

The entropic perspective goes beyond the Newtonian dynamics which is essentially a spatial motion. It is based on irreversible transformations of different forms of knowledge within the organizational knowledge spectrum. This perspective became possible only after the construction of a new knowledge metaphor by Bratianu and Andriessen (2008) - the energy metaphor. Figure 1 presents an illustration of this metaphor. In the source domain the authors put the concept of energy, and in the target domain the concept of knowledge. The transferred attributes from the source domain to the target domain are presented in Table 1. 
Table 1 - The transferred attributes of the source domain toward the target domain

\begin{tabular}{|l|l|}
\hline \multicolumn{1}{|c|}{ The source domain - Energy } & The target domain - Knowledge \\
\hline Energy is a field & Knowledge is a field \\
\hline Energy manifests in different forms & Knowledge manifests in different forms \\
\hline $\begin{array}{l}\text { One form of energy may transform into } \\
\text { another form of energy }\end{array}$ & $\begin{array}{l}\text { One form of knowledge may transform into } \\
\text { another form of knowledge }\end{array}$ \\
\hline $\begin{array}{l}\text { In an open system we may have energy } \\
\text { acquisition and energy loss }\end{array}$ & $\begin{array}{l}\text { In an open system we may have knowledge } \\
\text { acquisition and knowledge loss }\end{array}$ \\
\hline $\begin{array}{l}\text { Thermodynamics studies energy } \\
\text { transformation processes }\end{array}$ & $\begin{array}{l}\text { Knowledge dynamics studies knowledge } \\
\text { transformation processes }\end{array}$ \\
\hline
\end{tabular}

The fundamental property induced by the energy metaphor is that knowledge is a field. Thus, knowledge is conceived as an intangible and nonlinear entity which corresponds with its essence. If all the previous metaphors induced linearity and tangibility through the mapping process, the energy metaphor relaxes these limitations and assumes that knowledge is a field, which cannot be seen and cannot be touched like physical objects. Energy manifests through different forms like mechanical energy, thermal energy or electrical energy. Each one of these energy forms can be transformed into another energy form in concordance to the thermodynamics laws. Mapping these aspects from the source domain onto the target domain, we may consider three fundamental forms of knowledge: rational knowledge, emotional knowledge, and spiritual knowledge. Also, we may consider that each of these forms of knowledge can be transformed into another form of knowledge. Knowledge dynamics studies all of these transformations, going this way beyond the Newtonian dynamics of spatial motion.

The energy metaphor does not transfer the conservation law of energy, because knowledge can be created and destroyed.

This metaphorical approach leads us to consider organizational knowledge as a knowledge multifield construct composed of rational knowledge, emotional knowledge, and spiritual knowledge, as shown in figure 2. Each of these fields varies in time and in space within a given organization. 
Figure 2 - The multifield knowledge model

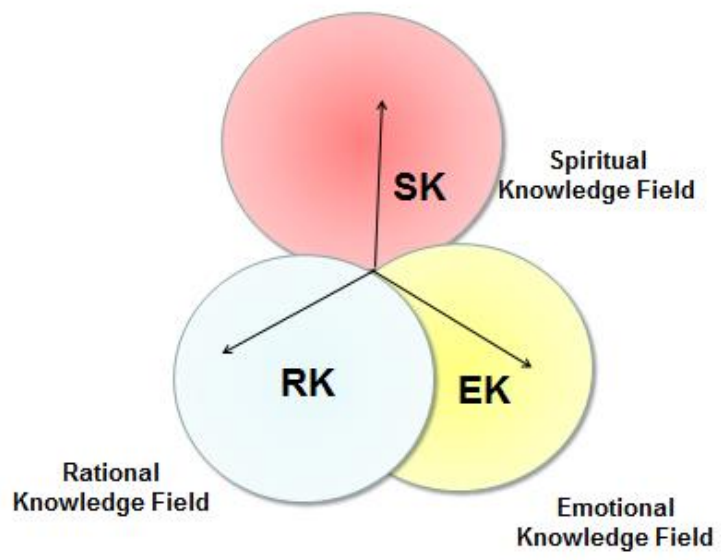

The rational knowledge field contains all rational knowledge which is expressed by the explicit knowledge owned by all the employees and also by the organization. It is the knowledge on which most of the knowledge management research focuses. It is that knowledge which can be expressed by using a natural or symbolic language (Davenport \&Prusak, 2000; Jashapara, 2011; Nonaka\& Takeuchi, 1995). Many philosophers starting with Plato considered that rational knowledge is the only knowledge we have since we cannot trust senses alone: "It follows that we cannot know through the senses alone since through the senses alone we cannot know that things exist. Therefore knowledge consists in reflection, not in impressions, and perception is not knowledge" (Russell, 1972, p. 153). Rational knowledge is a result of the mental work of our conscious zone of the brain and the use of a natural language like English, French or Japanese, or a symbolic language like the mathematical one. As Pinker (1994, pp. 4-5) remarks, "Language is a complex, specialized skill, which develops in the child spontaneously, without conscious effort or formal instruction, is deployed without awareness of its underlying logic, is qualitatively the same in every individual, and is distinct from more general abilities to process information or behave intelligently". At the organizational level, rational knowledge field contains all regulations, procedures, documents, patents, and knowledge bases created with the IT support. All the formal communications is done by using rational knowledge and the codification procedures. Codification is usually defined as a process of transforming an idea into an object, using a code that can range from an abstract to a metaphorical form. Knowledge codification increases organizational efficiency in decision-making (Bettiol et al., 2012; Prencipe\& Tell, 2001; Zollo\& Winter, 2002). 
The emotional knowledge field contains all the emotional knowledge owned by employees and that which is integrated in the organizational culture. Emotional knowledge could not be counted for by using the metaphors based on tangible objects. It is recognized by Nonaka and Takeuchi (1995), but only as a hidden component in the tacit knowledge (Bratianu\&Orzea, 2013). Emotional knowledge is generated by emotions and feelings. They are mostly processed by the unconscious zone of our brain and appear as wordless knowledge: "The simplest form in which the wordless knowledge emerges mentally is the feeling of knowing - the feeling of what happens when an organism is engaged with the processing of an object - and that only thereafter can interferences and interpretations begin to occur regarding the feeling of knowing" (Damasio, 1999, p. 26). Emotional knowledge is created by our sensory system as a reaction to any stimulus coming from the environment. The main role of emotional knowledge is to protect the life of the organism through a fast alert of a possible danger. Although education and culture influence the way emotions are expressed in a social context, they represent biologically determined processes constructed during a long evolutionary history. Damasio $(1999,2012)$ explains that emotions have two basic functions. The first function is to generate an information for our body and brain about a new stimulus or contextual situation at a given moment, while the second function is to prepare the body for action as a consequence of the first function. Related to emotional knowledge is the emotional intelligence which refers to "the capacity for recognizing our own feelings and those of others, for motivating ourselves, and for managing emotions well in ourselves and in our relationships" (Goleman, 1998, p. 317).

The spiritual knowledge field contains all the values, beliefs and existential states of minds within a given organization. If rational knowledge is a result of our understanding about the physical environment, and emotional knowledge represents the processed sensory information, spiritual knowledge reflects the understanding about our existence and our work. According to Maxwell (2007, p. 274), "We have to learn to see aspects of the world around us: stones, people, trees, sky. Equally, we have to learn to see meaning and value in the world around us, in our environment, in events, in human actions and lives". Spiritual knowledge becomes important especially for the knowledge workers who cannot be satisfied only with work for their livelihood. They have aspirations for becoming professionals or intellectuals which shows a high level of spiritual knowledge. The living companies (De Geus, 2002) are those which developed an adequate sustainable working spirituality and support their vision with a set of powerful values. They develop a stimulating organizational culture (Ghinea\&Bratianu, 2012; Schein, 2004) and a transformational leadership (Bratianu\&Anagnoste, 2011). Spiritual knowledge is processed by the spiritual 
intelligence, which is a fundamental intelligence like rational and emotional intelligences (Gardner, 2006; Zohar \& Marshall, 2000, 2004). As Zohar and Marshall (2004, p. 64) emphasize, "This is the intelligence with which we have access to deep meaning, fundamental values, and a sense of abiding purpose in our lives, and the role that this meaning, values and purpose play in our lives, strategies, and thinking processes".

In the Newtonian perspective, the organizational knowledge dynamics (OKD) is conceived as flow through the entire organization. "To the extent that organizational knowledge does not exist in the form needed for application or at the place and time required to enable work performance, then it must flow from how it exists and where it is located to how and where it is needed. This is the concept of knowledge flows" (Nissen, 2006, p. XX). This mechanical view is dominant at this moment in the knowledge management literature (Nonaka et al., 2008). The flow or stock-and-flow metaphors are successful due to their simplicity and intuitiveness.

In the entropic perspective, OKD is understood in terms of irreversible transformation of one form of knowledge into another form. Rational knowledge is transforming into emotional knowledge and spiritual knowledge, emotional knowledge is transforming into rational knowledge and spiritual knowledge, and spiritual knowledge is transforming into rational knowledge and emotional knowledge. These transformations happen randomly and reflect the continuous interactions between the knowledge fields of the organizational knowledge. In the entropic perspective, OKD is much more complex and approaches much better the real phenomena which have been revealed during many experiments done by cognitive scientists. For instance, O'Rorke and Ortony (1994, p. 238) state that "Emotions and cognition are inextricably intertwined. Feelings influence thoughts and actions, which in turn can give rise to new emotional reactions". Immordino-Yang and Damasio $(2007$, p. 8 ) introduce the concept of emotional thought to represent the transformation of rational knowledge into emotional knowledge and vice-versa: "Emotional thought encompasses processes of learning, memory, and decision making, in both social and nonsocial contexts". Emotional thought represents the influence of the mind on the body, and that of the body on the mind. A more complex transformation process will integrate rational, emotional and spiritual knowledge and will influence the motivation and decision-making processes in any organization (Hill, 2008; Gladwell, 2005; Zohar \& Marshall, 2004). These entropic transformations involving rational, emotional and spiritual knowledge integrate in the conceptualization and practice of corporate social responsibility (CSR) of any 
company (Basu\& Palazzo, 2008; Branson, 2011; Devinney, 2009) which is based on shared values and visionary leadership.

In a holistic perspective, OKD comprises the following complex phenomena: knowledge creation, knowledge acquisition, knowledge sharing, knowledge storing and retrieval, knowledge loss. Knowledge creation, knowledge acquisition and knowledge loss contribute directly to the knowledge balance of the organization, while the other processes contribute only to the distribution of knowledge within the organization. From the entropic perspective, knowledge sharing has an important effect on the increasing level of organizational entropy. Knowledge sharing has been considered in the knowledge management literature a major process with significant consequences on innovation (Bratianu et al., 2011; Davenport \&Prusak, 2000; Jashapara, 2011; Nonaka\& Takeuchi, 1995) and competitiveness. "The importance of this topic lays in the fact that it aims to link the individual level, where knowledge resides, and the organizational level, where knowledge is applied and attains value" (Sanchez et al., 2013, p. 391). Knowledge sharing leads to organizational entropy increase due to a new distribution of knowledge microstates which contributes to achieving the competitive advantage.

\section{Conclusions}

Organizational knowledge dynamics is a complex phenomenon which can be better understood by considering a holistic approach instead of focusing on single phenomena like knowledge creation, knowledge sharing, knowledge acquisition and knowledge loss. Also, it is necessary to base the analysis on the metaphorical thinking and entropic view, going beyond the Newtonian logic. In this perspective, the present paper shows how the first generations of metaphors shaped our understanding of knowledge and organizational knowledge dynamics. The dominant Newtonian logic leads to metaphors with physical objects and their attributes in their source domain which induced the idea of tangibility and linearity in treating knowledge. These serious limitations could be removed by introducing the energy metaphor and the basic concepts of thermodynamics. Thus, organizational knowledge is conceived as a multifield composed of rational, emotional, and spiritual knowledge fields. Knowledge from each field can be transformed into knowledge of another field, as a result of continuous interactions between these fields in all organizational activities and processes.

In the holistic approach of the organizational knowledge dynamics we focus on the organizational knowledge spectrum and on the entropic transformations of rational, emotional, and spiritual knowledge in the motivation 
and decision-making processes. Also, we showed that by developing knowledge sharing there is an increase in the organizational entropy as a result of a new distribution of knowledge microstates. The holistic perspective on organizational knowledge dynamics opens new interpretations and understanding of complex phenomena like motivation, innovation, corporate social responsibility, and achieving a competitive advantage.

\section{References}

[1] Andriessen, D. (2006). On the metaphorical nature of intellectual capital: A textual analysis. Journal of Intellectual Capital, 7(1), 93-110.

[2] Andriessen, D. (2008). Stuff or love? How metaphors direct our efforts to manage knowledge in organizations. Knowledge Management Research \& Practice, 6(1), 5-12.

[3] Andriessen, D. (2011). Metaphors in knowledge management. Systems Research and Behavioral Science, 28(2), 133-137.

[4] Atkins, P. (2010). The laws of thermodynamics: A very short introduction. Oxford: Oxford University Press.

[5] Basu, K. \& Palazzo, G. (2008). Corporate social responsibility: A process model of sensemaking. Academy of Management Review, 33(1), 122-136.

[6] Bejinaru, R. (2017). Knowledge strategies aiming to improve the intellectual capital of universities. Management \& Marketing. Challenges for the Knowledge Society, 12(3), 500523.

[7] Ben-Naim, A. (2012). Entropy and the second law: Interpretation and miss-interpretations. Singapore: World Scientific.

[8] Bettiol, M., Di Maria, E. \&Grandinetti, R. (2012). Codification and creativity: Knowledge management strategies in KIBS. Journal of Knowledge Management, 16(4), 550-562.

[9] Bolisani, E. \&Bratianu, C. (2017). Knowledge strategic planning: An integrate approach to manage uncertainty, turbulence and dynamics. Journal of Knowledge Management, 21(2), 233-253.

[10] Bolisani, E., Dono, A. \&Scarso, E. (2016). Relational marketing in knowledge-intensive business services: An analysis of the computer service sector. Knowledge Management Research \& Practice, 14(3), 319-328.

[11] Bolisani, E. \&Oltramari, A. (2012). Knowledge as a measurable object in business contexts: A stock-and-flow approach. Knowledge Management Research \& Practice, 10(3), 275-286.

[12] Borgo, S. \&Pozza, G. (2012). Knowledge objects: A formal construct for material, information and role dependence. Knowledge Management Research \& Practice, 10(3), 227-236.

[13] Boroditsky, L. (2000). Metaphoric structuring: Understanding time through spatial metaphors. Cognition, 75, 1-28.

[14] Branson, R. (2011). Screw business as usual. London: Virgin Books.

[15] Bratianu, C. (2009). The frontier of linearity in the intellectual capital metaphor. In Stam, C. \&Andriessen, D. (Eds.). Proceedings of the European Conference on Intellectual Capital, Inholland University of Applied Sciences, Haarlem, The Netherlands, 28-29 April 2009, pp. 97103. Reading: Academic Publishing Limited. 
[16] Bratianu, C. (2010). A critical analysis of Nonaka's model of knowledge dynamics. Electronic Journal of Knowledge Management, 8(2), 193-200.

[17] Bratianu, C. (2013). Nonlinear integrators of the organizational intellectual capital. In Fathi, M. (Ed.). Integration of practice-oriented knowledge technology: trends and perspectives (pp. 3-17). Heidelberg: Springer.

[18] Bratianu, C. (2014). Intellectual capital of the European universities. In Dima, A.M. (Ed.). Handbook of research on trends in European higher education convergence. Hershey: IGI Global.

[19] Bratianu, C. (2015). Developing strategic thinking in business education. Management Dynamics in the Knowledge Economy, 3(3), 409-429.

[20] Bratianu, C., Agapie, A., Orzea, I. \&Agoston, S. (2011). Inter-generational learning dynamics in universities. Electronic Journal of Knowledge Management, 9(1), 10-18.

[21] Bratianu, C. \&Andriessen, D. (2008). Knowledge as energy: A metaphorical analysis. In Harorimana, D. \& Watkins, D. (Eds.). Proceedings of the $9^{\text {th }}$ European Conference on Knowledge Management (pp. 75-82). Reading: Academic Publishing Limited.

[22] Bratianu, C. \&Anagnoste, S. (2011). The role of transformational leadership in mergers and acquisitions in emergent economies. Management \& Marketing, 6(2), 319-326.

[23] Bratianu, C. \&Bejinaru, R. (2017). Knowledge strategies for increasing IC of universities. In Lopez, I.T. \&Serrasqueiro, R. (Eds.). Proceedings of the $9^{\text {th }}$ European Conference on Intellectual Capital, InstitutoUniversitaria de Lisboa, Portugal, 6-7 April 2017, pp. 34-42. Reading: Academic Conferences and Publishing International.

[24] Bratianu, C. \&Bolisani, E. (2015). Knowledge strategy: An integrated approach for managing uncertainty. In Garlatti, A. \&Massaro, M. (Eds.). Proceedings of the $16^{\text {th }}$ European Conference on Knowledge Management (pp. 169-177), University of Udine, Italy, 3-4 September 2015. Reading: Academic Conferences and Publishing International.

[25] Bratianu, C. \&Orzea, I. (2010). Organizational knowledge creation. Management \& Marketing, 5(3), 41-62.

[26] Bratianu, C. \&Orzea, I. (2013). Emotional knowledge: The hidden part of the knowledge iceberg. In Janiunaite, B., Pundziene, A. \&Petraite, M. (Eds.). Proceedings of the $14^{\text {th }}$ European Conference on Knowledge Management (Vol.1, pp. 82-90), Kuanas University of Technology, Lithuania, 5-6 September 2013. Reading: Academic Conferences and Publishing International.

[27] Bratianu, C. \&Vasilache, S. (2010). A factorial analysis of the managerial linear thinking model. International Journal of Innovation and Learning, 8(4), 393-407.

[28] Chalidze, V. (2000). Entropy demystified: Potential order, life and money. USA: Universal Publishers.

[29] Damasio, A.R. (1999). The feeling of what happens: Body and emotion in the making of consciousness. New York: Harcourt.

[30] Damasio, A.R. (2012). Self comes to mind: Constructing the conscious brain. New York: Vintage Books.

[31] Davenport, T.H. \&Prusak, L. (2000). Working knowledge: How organizations manage what they know. Boston: Harvard Business School Press.

[32] De Geus, A. (2002). The living company: Growth, learning and longevity in business. London: Nicholas Brealey Publishing. 
[33] Devinney, T.M. (2009). Is the socially responsible corporation a myth? The good, the bad, and the ugly of corporate social responsibility. The Academy of Management Perspectives, 23(2), 44-56.

[34] Dumay, J. (2009). Intellectual capital measurement: A critical approach. Journal of Intellectual Capital, 10(2), pp. 190-210.

[35] Dumay, J. (2016). A critical reflection on the future of intellectual capital: From reporting to disclosure. Journal of Intellectual Capital, 17(1), 168-184.

[36] Elena Perez, S., Leitner, K.H., Secundo, G. \&Martinaitis, Z. (2015). Shaping new managerial models for European universities: The impact of reporting and managing IC. In Ordonez de Pablos, P. (Ed.). Intellectual capital in organizations: Nonfinancial reports and accounts (pp. 150-166). London: Routledge.

[37] Fauconnier, G. \& Turner, M. (2002). The way we think: Conceptual blending and the mind's hidden complexities. New York: Basic Books.

[38] Gardner, H. (2006). Five minds for the future. Boston: Harvard Business School Press.

[39] Georgescu-Roegen, N. (1999). The entropy law and the economic process. Cambridge, MA: Harvard University Press.

[40] Ghinea, V.M. \&Bratianu, C. (2012). Organizational culture modeling. Management \& Marketing, 7(2), 257-276.

[41] Gladwell, M. (2005). Blink: The power of thinking without thinking. New York: Back Bay Books.

[42] Goleman, D. (1998). Working with emotional intelligence. London: Bloomsbury.

[43] Grant, R.M. (1996). Toward a knowledge-based theory of the firm. Strategic Management Journal, 17 (Winter special issue), 109-122.

[44] Grondin, S. (2010). Timing and time perception: A review of recent behavioral and neuroscience findings and theoretical directions. Attention, Perception \& Psychophysics, 72(3), 561-582.

[45] Guthrie, J., Ricceri, F. \&Dumay, J. (2012). Reflections and projections: A decade of intellectual capital accounting research. The British Accounting Review, 44, 68-82.

[46] Habersam, M., Piber, M. \&Skoog, M. (2013). Knowledge balance sheets in Austrian universities: The implementation, use and re-shaping of measurement and management practices. Critical Perspectives on Accounting, 24, 319-337.

[47] Handscombe, R.D. \& Patterson, E.A. (2004). The entropy vector: Connecting science and business. Singapore: World Scientific.

[48] Hill, D. (2008). Emotionomics: Leveraging emotions for business success. Revised Edition. London: Kogan Page.

[49] Immordino-Yang, M.H. \&Damasio, A.R. (2007). We feel, therefore we learn: The relevance of affective and social neuroscience to education. Mind, Brain, and Education, 1(1), p. 3-10.

[50] Jashapara, A. (2011). Knowledge management: An integrated approach. $2^{\text {nd }}$ Edition. London: Financial Times/Prentice Hall.

[51] Lakoff, G. \& Johnson, M. (1980). Metaphors we lived by. Chicago: The University of Chicago Press.

[52] Lakoff, G. \& Johnson, M. (1999). Philosophy in the flesh: The embodied mind and its challenges to the western thought. New York: Basic Books. 
[53] LeDoux, J. (1998). The emotional brain: The mysterious underpinnings of emotional life. New York: Phoenix.

[54] Leonard-Barton, D. (1995). Wellsprings of knowledge: Building and sustaining the sources of innovation. Boston: Harvard Business School Press.

[55] Maxwell, N. (2007). From knowledge to wisdom: A revolution for science and the humanities. $2^{\text {nd }}$ Edition. London: Pentire Press.

[56] Moser, K.S. (2000). Metaphor analysis in psychology - Method, theory, and fields of application, Art, 21, 1-8.

[57] Nisbett, R.E. (2003). The geography of thought: How Asians and Westerners think differently ... and why. New York: Free Press.

[58] Nissen, M.E. (2006). Harnessing knowledge dynamics: Principled organizational knowledge \& learning. London: IRM Press.

[59] Nonaka, I. (1994). A dynamic theory of organizational knowledge creation. Organization Science, 5(1), 14-37.

[60] Nonaka, I. \& Takeuchi, H. (1995). The knowledge-creating company: How Japanese companies create the dynamics of innovation. New York: Oxford University Press.

[61] Nonaka, I., Toyama, R. \&Hirata, T. (2008). Managing flow: A process theory of the knowledge-based firm. Houndmills: Palgrave Macmillan.

[62] O'Dell, C. \& Hubert, C. (2011). The new edge in knowledge: How knowledge management is changing the way we do business. New York: John Wiley \& Sons.

[63] O’Rorke, P. \&Ortony, A. (1994). Explaining emotions. Cognitive Science, 18(2), 283-323.

[64] Pinker, S. (1994). The language instinct: How the mind creates language. New York: Harperperenial.

[65] Pinker, S. (2008). The stuff of thought: Language as a window into human nature. New York: Pinguin Books.

[66] Prencipe, A. \& Tell, F. (2001). Inter-project learning: Processes and outcomes of knowledge codification in project-based firms. Research Policy, 30(9), 1373-1394.

[67] Russ, M. (1999). The edge of organization: Chaos and complexity theories of formal social systems. Thousand Oaks: SAGE Publications.

[68] Russell, B. (1972). A history of western philosophy. New York: Simon and Schuster.

[69] Sanchez, J.H., Sanchez, Y.H., Collado-Tuiz, D. \&Cebrian-Tarrason, D. (2013). Knowledge creating and sharing corporate culture framework. Proceedia: Social and Behavioral Sciences, 74, 388-397.

[70] Schein, E.H. (2004). Organizational culture and leadership. $3^{\text {rd }}$ Edition. San Francisco: JosseyBass.

[71] Spender, J.C. (1996). Making knowledge the basis of a dynamic theory of the firm. Strategic Management Journal, 17 (Winter special issue), 45-62.

[72] Zohar, D. \& Marshall, I. (2000). SQ: Spiritual intelligence: The ultimate intelligence. London: Bloomsbury.

[73] Zohar, D. \& Marshall, I. (2004). Spiritual capital: wealth we can live by. San Francisco: BerrettKoehler Publishers.

[74]Zollo, M., \&Winter, S.G. (2002). Deliberate learning and the evolution of dynamic capabilities. Organization Science, 13(3), 339-351. 